\title{
A Practical Approach to Teach Web Programming Course
}

\author{
Margaret R.E. ${ }^{1}$, Vinod A. M. ${ }^{2}$, Tejonidhi M. R. ${ }^{3}$ \\ ${ }^{1}$ Department of Master of Computer Applications, Malnad College of Engineering, Hassan - 573202, Karnataka, India. \\ 'margaret.re2011@gmail.com, ${ }^{2}$ amv@mcehassan.ac.in, ${ }^{3}$ tejonidhimr@yahoo.co.in
}

\begin{abstract}
Web programming is an interesting and important course, which commands innovative methods to reach the students in large. This paper describes an approach to effective teaching of this course in our department. The traditional method of teaching this course includes the use of black board and power point presentations. But to enable students to apply the learned concepts in real time projects, the usage of different constructs was demonstrated live in the classrooms using a computer projector. The highlight of the course was to make students in batches of 2 or 3 to develop a simple web portal and host it on internet. The whole process enhanced student learning, their confidence to take up live projects and fostered communication skills and human relationship. This indirectly led to the development of better student community in the department, hence the institute.
\end{abstract}

Keywords: Web programming, Effective teaching.

\footnotetext{
Margaret R.E.

${ }^{1}$ Department of Master of Computer Applications, Malnad College of Engineering, Hassan - 573202, Karnataka, India.
}

\section{Introduction}

The web technologies are changing so fast that always there is a need for the qualified professionals. Now a day's computer-based application, particularly information systems and e-commerce uses the web technologies like HTML, XHTML, Cascading Style Sheets (CSS), XML, JavaScript, PHP, MySQL, and Ruby on rails, Ajax, CGI/Perl for designing user interfaces. These applications are referred to as webbased applications. Developing web-based applications requires learning programming techniques, methods, components and skills on the web environment are necessary for the post graduate students like MCA (Master of Computer Applications). The post graduates must have more practical knowledge so that they can implement the real time projects. The proposed approach is different from the traditional approach. In traditional approach teacher only teaches according to the syllabus defined by the university. Assessment of the students was based on the end exam and internal tests. The benefits of proposed approach are to enhance students learning and to gain better technical knowledge. By doing mini projects students will get an opportunity for detailed investigation skills on worthy topics, enables them to face challenging problems, to learn better from the experiences and gained knowledge skills.

\section{Related Work}

R. Byrd, M. Beier [1] Abilene Christian University, 
have designed web development curriculum to expose students to the various web technologies, including server configuration, security, networking, employing databases to create interactive content, and human computer interface optimization. Skills and techniques found critical in this study were the ability to simultaneously manage multiple working environments, application aspects, and current technologies.

Vasantha Lakshmi.M, [2] presents a new approach to the outcome based education compared to the traditional approach. The new approach is based on the modification to the traditional approach. Outcome based education which purely depends on the performance of the students. Outcome- based learning is learner driven and it aims at achieving program outcomes by defining the assessment method. The method used by Vasanth et al [2] is seminar.

Utku Köse,[3] have proposed A web based system for project-based learning activities in "web design and programming" course. This paper presents Project-based learning (PBL) as a learning approach that organizes students' learning activities around projects. This gives students the opportunities for detailed investigations on worthy topics and enables them to learn from the experiences and apply gained knowledge, skills and attitudes to real cases in their lives.

Xusheng Wang[4] presents a practical way to design and implement the course on web programming, so that a computer science student can learn and master necessary knowledge and skills for efficiently developing interactive web-based database-driven applications. Considering that many students had not systematically learned the basic client- side webdevelopment techniques and software tools, the course allotted one third of total duration to review and teach XHTML, CSS, HTTP, JavaScript, and Macromedia Dreamweaver and Fireworks. This paper discusses the details of the design and implementation of the web programming course including course contents, structure, implementation, demonstration, assignments, final project, outcomes and feedback.

\section{Structure}

In a traditional approach, emphasize is mainly on the coverage of syllabus prescribed by the university.
The teaching of web programming has been done, usually, by traditional method or slightly sophisticated teacher-centred methods rather than modern student-oriented applications and techniques. The transmission of knowledge and information has been realized with the usual form of lectures or discussions. Even though the student has freedom to think innovatively and implement his ideas in a creative way beyond the curriculum, he/she is bound by the rules and regulations of university.

The following point indicates the issues in traditional based approach of teaching.

口 In traditional method, teacher delivers lecture and students will be passive learners.

口 Teacher focuses on the syllabus prescribed by the university within the given duration and bounded by text books. Students focus on semester end exam.

( Since the syllabus is prescribed by the university teacher cannot alter or go beyond the syllabus.

口 Teacher focuses on semester end examination pass percentage of the students.

u Students are evaluated based on the internal marks and examination marks.

( ) Minimum amount of team work, interpersonal relationship among students.

( There is no privilege to a teacher to allocate marks, for the assignments and activities; hence students will not show interest in doing them sincerely.

In theory classes web programming constructs were demonstrated online using a computer. This creates interests among the students and gets their doubts clarified. This further motivates them to develop their own web pages. The students are grouped into batches of 2 or

3 members and they were given mini projects to create web portals of their choice and to host it on the internet. This process enhances learning and practical skills of students. Also it leads to better communication and inter relationship among students. The benefits of this approach are

口 - Enriched student's communication skills and u better human relationships.

u - Practical implementation of the knowledge gained. 
प Teachers will guide, monitor and clarify the students

૫ Teacher can observe students collectively and individually.

( Enhances positive relationship with teachers and students.

\section{AssessmentAnd Results}

Assessment is the important phase to measure the performance of students learning. This approach emphasizes on the different aspects of the learner's abilities, such as analysing, designing and customized implementing using modern tools and technologies. This increases creativity, critical thinking and communication skill. It helps in the overall personality development. Since we have followed online demonstration of constructs, tags etc. of HTML, XHTML, Cascading Style Sheets (CSS), XML, JavaScript, PHP, MySQL, and Ruby on rails, Ajax, CGI/Perl to students and make them to create their own web portal and to host it on the internet. Few students faced difficulties which were solved by their peers and faculty. But students were very happy to see their web portals up on the internet. Some students find it difficult. We have conducted a survey and given a questionnaire of 5 likert-scale questions (based on 5 scale system: 1 being the least and 5 being the maximum), and questions were as follows.

प Q1 - Have you enjoyed the web programming course?

Q Q2 - Have you understood the course better than if it had been lectured in the traditional way?

口 Q3 - Have you enjoyed and undergone knowledge sharing in the project group?

口 Q4 - Did you get more practical knowledge than in traditional method of teaching?

Q Q5 - Did you get the confidence of building the website on your own?

The Table-1 shows the students feedback survey for 50 students. Columns in the table represents the likert scale rating (based on 5 scale system: 1 being the least and 5 being the maximum) and each row represents question numbers and corresponding rating obtained from the students. It is found that around $75 \%$ of the students enjoyed and given a positive feedback and $25 \%$ felt difficult in completing the project.
Table 1: Student feedback Survey

\begin{tabular}{|c|c|c|c|c|c|}
\hline \multirow{2}{*}{$\begin{array}{c}\text { Question } \\
\text { Number s }\end{array}$} & \multicolumn{5}{|c|}{ Attribut es in Nu mber } \\
\cline { 2 - 6 } & 5 & 4 & 3 & 2 & 1 \\
\hline Q1 & 35 & 6 & 5 & 1 & 3 \\
\hline Q2 & 30 & 10 & 5 & 3 & 2 \\
\hline Q3 & 45 & 5 & 0 & 0 & 0 \\
\hline Q4 & 32 & 8 & 8 & 0 & 2 \\
\hline Q5 & 20 & 8 & 8 & 4 & 1 \\
\hline
\end{tabular}

The bar chart shows the student feedback survey

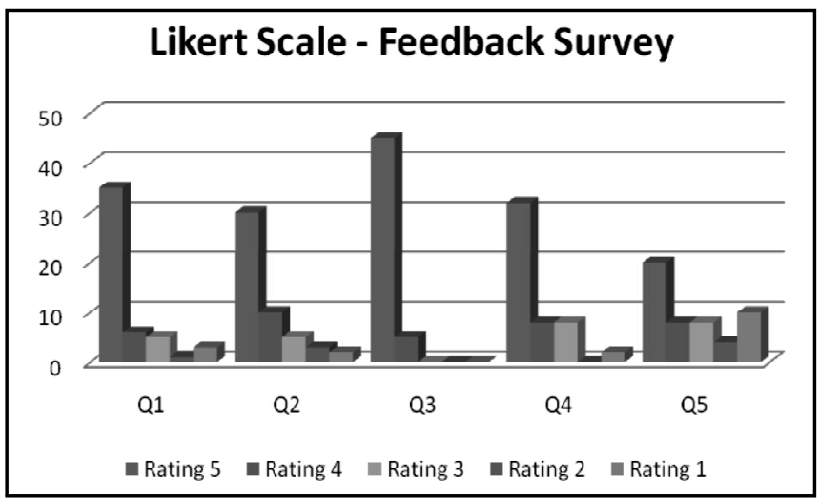

Fig. 1: Bar chart for Feedback Survey

The Table-2 shows the students result analysis. During year 2014-15 enhanced web programming learning is implemented and the result of 2014-15 is compared with the previous year 2013-14. We found an increase in the performance of the students. This shows that the proposed method of teaching web programming course has made students students learning more effective.

Table 2: Result Analysis

\begin{tabular}{|c|c|c|c|c|}
\hline Year & Pass & Second class & First class & Distinction \\
\hline $2013-14$ & 20 & 15 & 8 & 7 \\
\hline $2014-15$ & 15 & 13 & 10 & 12 \\
\hline
\end{tabular}

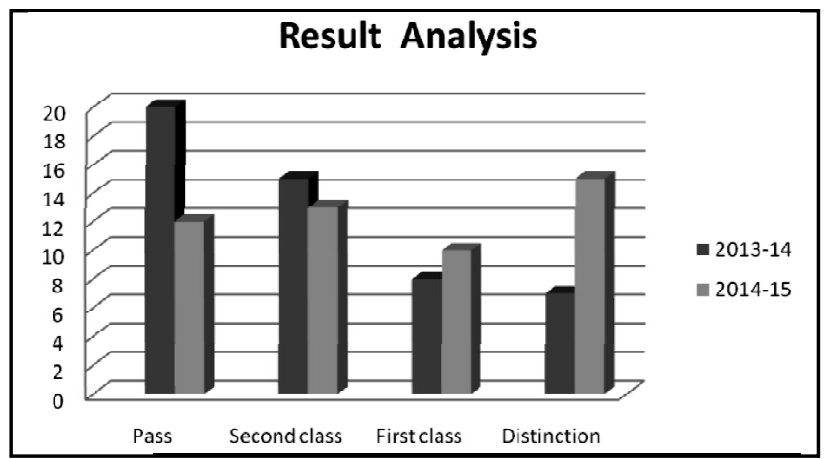

Fig. 2: Bar chart for Result Analysis 


\section{Conclusion}

In this paper a different approach has been experimented to teach web programming course in an effective manner. This emphasizes on the student oriented teaching, making students active learners. Students enjoyed learning by doing practical's like creating web pages and web portals and hosting it on the internet. The complete process has results in enhanced knowledge communications skills, better inter relationships among students community. It increased professional and ethical responsibility and leads to lifelong learning. Many of the graduate attributes can be achieved using enhanced learning, which otherwise would not be possible.

\section{References}

[1]R. Byrd, M. Beier,Abilene Christian University, Abilene, Texas, United States, Web Programming Curriculum: What Changes, What Remains the Same Over Time.
[2] Vasantha Lakshmi.M, "Outcome-Based Teaching: Microwave And Radar", Department of Telecommunication, BMS College of Engineering, Bangalore, India, 978-1-4799-68763/14, 2014, IEEE

[3]Utku Köse,[3] Afyon Kocatepe University, Distance Education Vocational School, ANS Campus, Afyonkarahisar, "A Web Based System For Project- Based Learning Activities In "Web Design And Programming", Project-based learning (PBL).

[4] Xusheng Wang, "A Practical Way To Teach Web Programming In Computer Science", Department of Computer Science, The University of Texas Pan American, 1201 W University Drive, Edinburg, TX,JCSC 22, October-2006. 